\section{P101 Integration of a Field Experience Component in the Child Health Assessment in the Pacific (CHAP) Undergraduate Summer Fellowship Program}

Marie K. Fialkowski, PhD, MS, RD, LD, mariekf@hawaii. edu, University of Hawaii at Manoa, 1955 East West Road, AgSci 216, Honolulu, HI 96822; M'Randa Sandlin, PhD, University of Hawaii at Manoa; Rachel Novotny, PhD, RD, LD; Margaret Hattori-Uchima, PhD, RN, University of Guam; Patricia Coleman, BS, Northern Marianas College; Chyrstie Naeole, PhD, Chaminade University

Objective: To evaluate the field experience component of the Child Health Assessment in the Pacific Undergraduate Summer Fellowship Program (CHAP).

Theory, Prior Research, Rationale: Experiential learning is a pedagogical approach to reinforce concepts taught in a didactic learning environment. In a region with limited childhood health assessment programs, experiential learning may increase the likelihood that students learn key CHAP concepts.

Description: The target audience was ten undergraduate students participating in CHAP from institutions in Hawaii, Commonwealth of the Northern Mariana Islands, Chuuk, and Guam. Students were paired with a mentor for a child health assessment summer field experience. Students completed two online courses, a one-week hands-on training, and monthly virtual sessions for background knowledge and skills. Each student had a $\$ 400$ budget. Upon completion, students submitted a written and video summary. Students were provided feedback using program rubrics.

Evaluation: Eight students completed all field experience components with at least a satisfactory performance. Eight students provided field experience feedback through an online end of program evaluation. All eight students strongly agreed/agreed that the field experience was a valuable component, that their mentor provided meaningful guidance, and that they were provided with satisfactory assistance. Positive aspects included applying their skills, creativity, and leadership, as well as engaging with the community. Areas of improvement were related to providing clearer expectations and having more time to complete the experience, and for hands-on training.

Conclusions and Implications: The field experience contributed positively to the CHAP student learning experience. Long-term follow-up is needed to determine if these skills are being applied by this interdisciplinary cohort of students post-program.

Funding: NIFA

\section{P102 Meeting the Grand Challenges}

Suzanne Stluka, MS, RD, Suzanne.Stluka@sdstate.edu, South Dakota State University Extension SWG 435, Box 2275A, Brookings, SD 57007; Timothy Nichols, PhD, South Dakota State University

Objective: Overview the project, including its rationale, key collaborators and funding sources; highlight program features such as transdisiplinary courses, systems thinking training, 'personal responsibility projects', undergraduate research, social media integration, and community partnerships; share formative assessment results indicating strong positive student and faculty participation and learning outcomes; engage presentation attendees in a discussion about other innovative ways to help students prepare to meet the grand challenges. From our project, several student research efforts have been presented on campus and at regional and national venues.

Target Audience: This presentation highlights a collaborative project to develop a food/agricultural sciences workforce that is well prepared to meet the grand challenges associated with USDA priority need areas, i.e. hunger/food security, sustainable energy, childhood obesity, climate change, and food safety.

Description of Course or Curriculum: Program components include transdisciplinary grand challenge courses; undergraduate research and service learning experiences in the priority need areas; and development of grand challenge youth outreach materials delivered via student interns through Extension and Boys and Girls Clubslocally and in tribal communities. A special certificate designates students as 'Grand Challenges Scholars' at graduation.

Conclusions and Implications: Progress has been made toward cultivating student success among program participants. Survey responses indicate students feel more aware of the grand challenges, have a stronger sense of personal connection to the challenges, have thought critically and creatively about solutions to the challenges, have engaged their communities on grand challenge issues, and, importantly, feel better prepared to help meet the challenges.

Funding: USDA

\section{P103 Phenomenology of Classroom Teachers' Experience with Nutrition Education}

Elisha Hall,PhD, RD,LD, elisha@huskers.unl.edu, Feeding Texas, 1524 South I H 35 \#342, Austin, TX 78704; Weiwen Chai, PhD, University of Nebraska-Lincoln; Julie Albrecht, PhD, RD

Objective: Nutrition education delivered by classroom teachers is an intervention format increasing in popularity, however few in-depth qualitative studies have explored the experience of nutrition education with teachers. The objective of this study was to explore how elementary school teachers describe their experience with nutrition education.

Study Design, Setting, Participants, Intervention: A qualitative transcendental phenomenological research design was utilized, with a post-positivism paradigm to form the foundation of the study. The intent of this research design is to describe commonalities of a lived experience (delivering nutrition education) for several individuals. Early elementary (K-2) school teachers were

Continued on page S64 
P103 (continued)

sampled to saturation, with a total of 10 teachers participating. Semi-structured interviews, observations, and document analysis were conducted with each teacher.

Outcome Measures and Analysis: Inductive coding was used to determine invariant constituents of the experience, reduce constituents to categories, and cluster categories into overarching themes. Reliability and validity strategies, such as intercoder agreement and member checking, were conducted to strengthen results.

Results: Five core themes were identified, including: Multiple meaningful roles in nutrition education, importance of nutrition education, perceived influences on behavioral predictors and behavior, personal motivation, and barriers to education.

Conclusions and Implications: Findings demonstrate a complex set of experiences and perspectives integral to successfully delivering classroom-based nutrition education. Nutrition experts should involve school teachers throughout the program development and assessment process of any classroom-based nutrition education intervention to address teachers' perspectives and facilitate successful delivery. Although the present sample size was acceptable for qualitative research, a quantitative study should be developed to determine generalizability of results.

Funding: USDA

\section{P104 Qualitatively Assessing Undergraduate Dietetic Students' Abilities to Counsel in a Nutrition Therapy Class}

Katie Horrell, BS, Eastern Illinois University;

Jeanette Andrade,PhD, LDN, RDN, jmevans@eiu.edu, Eastern Illinois University, 600 Lincoln Avenue, Charleston, IL 61920

Objective: To qualitatively assess undergraduate dietetic students' counseling abilities in a nutrition therapy class. Study Design, Setting, Participants, Intervention: A qualitative study was conducted at a Mid-Western University in Fall 2016 in a nutrition therapy class. Eight senior-level undergraduate dietetic students; 2 males and 6 females, were enrolled in the class. Students met with a graduate student, who acted as the patient, for five case studies throughout the course. These case studies were based on a chronic condition. Students were informed how to counsel at the beginning of the course, but not guided throughout the course on finetuning their counseling abilities. Students were provided with a medical chart 24 hours prior to the counseling session. The graduate student sat outside in a semi-private hallway and was counseled by each student for 20 minutes.

Outcome, Measures, Analysis: After each counseling session, the graduate student assessed each student based on a ten-point counseling criteria that she created. Transcript analysis of responses from the ten criterion followed content analysis methodology.
Results: Over the course of 16 weeks, students overall improved their counseling abilities. Particularly, in the criterion: building rapport, compassion/empathy, prioritizing important information, respect of personal/religious preferences and scope of questions. However, students did not appear to improve in the criterion: eye contact, body language and preparation. Nutrition jargon remained at a consistent low throughout the five sessions.

Conclusions and Implications: The evidence supports that students who are exposed to live, interactive counseling sessions will improve their counseling abilities. Effectively, providing students with this opportunity to counsel in the classroom will help them as future RDNs.

Funding: Winkleblack Grant

\section{P105 Evaluation of Cooking for Kids: Culinary Training Program for Oklahoma School Child Nutrition Professionals on Students' Consumption of School Meals}

Bradyn Powell, BS, bradyn.powell@okstate.edu, Oklahoma State University, 301 Human Sciences, Stillwater, OK 74078; Deana Hildebrand, PhD, LDN, RD, SNS, Oklahoma State University; Barbara Brown, PhD, LDN, RD; Gail Gates, PhD, RD, FAND

Objective: Determine if Cooking for Kids culinary training affected availability of freshly prepared foods in school meals, the extent to which marketing strategies were implemented and students' meal component consumption before and after training.

Description: The 2010 Healthy Hunger-Free Kids Act improved the nutritional quality of school meals; but created implementation strategies for schools including lack of kitchen infrastructure, staffs' time and culinary skills to prepare meals, and concerns that students would not be accepting of new foods. Cooking for Kids, developed under the principles of the Community Readiness Model, utilizes professional chefs to teach essential culinary skills and on-site consultations to address menu planning related practices specific to a school district.

Evaluation: A meal component consumption analysis was conducted in spring 2014 (681 matched trays) and fall 2016 (537 matched trays) in three pilot schools. Personal interviews were conducted with the Child Nutrition Director (CND) at each school to evaluate changes in use of convenience foods and marketing strategies from pre- to post-intervention. Schools used less convenience foods for entrees and offered more salad bars. There was no negative impact on entree consumption ( $\mathrm{P}=0.878)$, an increase in grain $(\mathrm{P}=0.011)$ and fruit $(\mathrm{P}=0.000)$ meal components and a decrease in vegetable consumption $(\mathrm{P}=0.000)$.

Conclusions and Implications: If schools focus on preparing food from scratch and incorporate marketing strategies, students' consumption of school meals may improve. Further use of marketing strategies, especially for vegetables, may be beneficial. 